\title{
High glucose and homocysteine synergistically affect the metalloproteinases-tissue inhibitors of metalloproteinases pattern, but not TGFB expression, in human fibroblasts
}

\author{
A. Solini • E. Santini • M. Nannipieri • E. Ferrannini
}

Received: 16 February 2006 / Accepted: 16 June 2006 / Published online: 1 August 2006

(C) Springer-Verlag 2006

\begin{abstract}
Aims/hypothesis Atherosclerosis is particularly aggressive in patients with diabetes. Hyperhomocysteinaemia causes oxidative stress and cytokine secretion: its atherogenic effect is mediated by an enhanced inflammatory response. Matrix metalloproteinases (MMPs) regulate extracellular matrix degradation and remodelling, and contribute to the vulnerability of the atherosclerotic lesion. Fibroblasts contribute to collagen biosynthesis and participate in plaque remodelling via expression and release of MMP2 and MMP9. To explore the role of hyperhomocysteinaemia in cellular pathways involved in plaque growth and stability in diabetic patients, we studied the effect of hyperhomocysteinaemia in human fibroblasts grown in the presence of normal or high glucose concentrations.

Materials and methods In fibroblasts of five normal subjects, grown at 5.5 or $22 \mathrm{mmol} / 1$ glucose and treated with homocysteine, we determined: (1) MMP2, MMP9 and tissue inhibitor of metalloproteinases (TIMP)-1 (an MMP inhibitor) production by western blot analysis; (2) their activity by zymography; (3) TGFB1 expression by real-time PCR; and (4) TGFB, fibronectin and IL6 release by ELISA. Results Hyperhomocysteinaemia increased the production and enzymatic activity of MMP2 and MMP9, the effect being more pronounced in high glucose. Conversely, TIMP1 production was reduced by hyperhomocysteinaemia in both conditions, especially in high glucose. Hyper-

A. Solini $(\varangle) \cdot$ E. Santini $\cdot$ M. Nannipieri $\cdot$ E. Ferrannini

Department of Internal Medicine, University of Pisa,

Via Roma, 67,

I-56100 Pisa, Italy

e-mail: a.solini@med.unipi.it

E. Ferrannini

C N R Institute of Clinical Physiology,

Pisa, Italy
\end{abstract}

homocysteinaemia also stimulated IL6 release, at least in part through nuclear factor- $\mathrm{kB}$ activation. TGFB1 expression was not affected by hyperhomocysteinaemia either in normal or in high glucose.

Conclusions/interpretation Homocysteine upregulates the MMP-TIMP pathway and IL6 release, the effect being stronger in the presence of high glucose. These actions of homocysteine may contribute to the increased atherogenesis observed in diabetic patients with poor metabolic control.

Keywords Atherosclerosis - Diabetes · Homocysteine · Interleukin-6 $\cdot$ Metalloproteases $\cdot$ TGF $\beta$ - TGFB
Abbreviations
ECM extracellular matrix
Hcy hyperhomocysteinemia
$H P R T$ hypoxanthine-phosphoribosyl-transferase
MMP metalloproteinases
NAC $\quad N$-acetyl-L-cysteine
$\mathrm{NF}-\mathrm{kB}$ nuclear factor- $\mathrm{kB}$
PKC protein kinase $\mathrm{C}$
TIMP tissue inhibitor of metalloproteinases

\section{Introduction}

Atherosclerosis is a complex process characterised by the accumulation of modified lipids, monocytes, and macrophage foam cells containing cholesteryl ester, and by the deposition and degradation of extracellular matrix (ECM) components in the vascular wall [1]. ECM degradation and remodelling, which may ultimately contribute to the vulnerability of the atherosclerotic lesion and promote plaque rupture, is mainly due to active forms of matrix metalloproteinases (MMPs), also known to be involved in 
the pathogenesis of myocardial infarction and restenosis [2]. Numerous reports have shown that MMP9 and MMP2 (expressed as latent proenzymes by the cells of the arterial wall), as well as MMP1 (interstitial collagenase), are present in various human atherosclerotic lesions [3, 4]. Their activity is modulated by a family of endogenous tissue inhibitors of metalloproteinases (TIMPs). Recently, TIMP1, the inducible form, has been identified as a multifunctional molecule that participates in wound healing and regeneration, and also influences cell morphology and survival, tumor metastasis, angiogenesis, and inflammatory responses [5]. Alterations in the expression of MMP or in the balance between MMP and TIMPs may have a profound impact on various biological processes $[6,7]$.

Interleukin-6 is a proinflammatory cytokine known to play a crucial role in the pathogenesis of atherosclerosis. It acts locally by influencing adhesion, migration and invasion of leucocytes into vascular walls. Its systemic concentrations are used as a marker for adverse prognosis [8]. Fibroblasts are not only the major contributor to collagen biosynthesis, but also participate in plaque remodelling via expression and release of MMP2 and MMP9 [9]; moreover, they release abundant amounts of IL6, particularly in the presence of high glucose concentrations [10]. It has been repeatedly shown that primary skin fibroblasts exhibit at least some of the characteristics and functional properties of vascular wall cells $[11,12]$ and share with them a common genesis [13].

Hyperhomocysteinaemia (Hcy) is generally considered to be a risk factor for coronary, cerebral, and peripheral vascular disease [14, 15]. Elevated plasma homocysteine levels may cause endothelial damage [16, 17], vascular thrombosis, oxidative stress [18], and cytokine secretion [19]. However, the mechanisms mediating these vascular changes have not been elucidated. Hcy has been shown to induce elastin deterioration by increasing metal-dependent elastase activity, and to promote TIMP1 expression and synthesis in a variety of cells [20, 21]. Additionally, recent reports suggest Hcy may exert part of its atherogenic effect by modulating MMP activity in mononuclear cells [22], potentially leading to degradation of ECM within the atherosclerotic lesion. Finally, Hcy may stimulate IL6 production by monocytes and human vein endothelial cells $[23,24]$.

Even though elevated homocysteine levels contribute to the development of atherosclerosis independently of classical cardiovascular risk factors in diabetic subjects $[25,26]$, the relationship between Hcy and diabetes is still debated. Plasma homocysteine levels have been reported to be normal, reduced or elevated in patients with diabetes [27-29]. While plasma homocysteine has been found to strongly correlate with insulin levels [30], its interactions with glucose levels are less clear. The present work aimed at exploring the role of Hcy, and its interaction with hyper- glycaemia, in cellular pathways involved in plaque growth and stability in diabetes.

\section{Subjects, materials and methods}

Cells

Fibroblasts were obtained from a skin biopsy performed on the forearm surface of five healthy volunteers. All the volunteers gave their written informed consent, and the procedure received the approval of the ethics committee of the University of Padua.

Each biopsy was immediately split into two cell batches and cultured in DMEM (Invitrogen, San Giuliano Milanese, Italy) containing $10 \%$ FCS at two different glucose concentrations $(5.5$ and $22 \mathrm{mmol} / \mathrm{l})$ at $37^{\circ} \mathrm{C}$. After the fourth passage, cells were collected and stored in liquid nitrogen. All experiments were performed in the fifth to eighth passage after 24-h serum deprivation. Fibroblasts were incubated with 10 or $100 \mu \mathrm{mol} / \mathrm{l}$ DL-homocysteine (Fluka, Milan, Italy) for $6 \mathrm{~h}$ in a $\mathrm{CO}_{2}$ incubator $\left(37^{\circ} \mathrm{C}, 5 \% \mathrm{CO}_{2}\right)$. The nuclear factor- $\mathrm{kB}(\mathrm{NF}-\mathrm{kB})$ inhibitors were EGTA, $\mathrm{N}$-acetyl-L-cysteine (NAC) and calphostin C (all from Sigma Aldrich, Milano, Italy).

Metalloproteinase and tissue inhibitor determination

MMP2, MMP9 and TIMP1 proteins were determined by western blot analysis. Briefly, proteins were extracted in radioimmunoprecipitation buffer $(1 \times$ PBS, $1 \%$ Nonidet P-40, $0.5 \%$ sodium deoxycholate and $0.1 \%$ SDS) containing freshly dissolved protease inhibitors and blocked with $5 \%$ non-fat dry milk in Tris-buffered saline Tween- 20 at $4{ }^{\circ} \mathrm{C}$. Denatured protein $(30 \mu \mathrm{g}$ total proteins for MMP, $50 \mu \mathrm{g}$ total proteins for TIMPs) was subjected to SDS-PAGE on a $10 \%$ (for MMP2 and -9) or 15\% (for TIMP1) polyacrylamide gel (Bio-Rad, Hercules, CA, USA), and separated proteins were electrically transferred on to polyvinylidene difluoride membranes (Bio-Rad, Hercules, CA). After blocking the non-specific background, these membranes were incubated with the antibodies for anti-rabbit polyclonal MMP2 (AB809; 1:1,000), MMP9 (AB804; 1:1,000), and TIMP1 (AB8116; 1:1,000) for $1 \mathrm{~h}$ at room temperature. The membranes were then washed with Tween-20 buffer and incubated with goat anti-rabbit horseradish peroxidase $(1: 1,000)$ for $1 \mathrm{~h}$ at room temperature. Signals were immunodetected by chemiluminescence (Amersham Pharmacia Biotech, Buckinghamshire, UK), and the intensities of the band analysed densitometrically using the NIH program 1.62 (Scion Corporation, Frederick, MD, USA).

The activity of MMP2 and MMP9 in the supernatants was assessed by zymography. Equal aliquots of conditioned 
culture media from an equal number of cells were fractionated using precast zymogram gels containing gelatin, according to the manufacturer's protocol (Novex, San Diego, CA, USA). After electrophoresis, the gels were incubated in renaturing buffer $(50 \mathrm{mmol} / 1 \mathrm{Tris}-\mathrm{HCl}[\mathrm{pH}$ 7.4], 2\% [vol/vol] Triton X-100) for $30 \mathrm{~min}$ at room temperature and then incubated in developing buffer (50 mmol/1 Tris- $\mathrm{HCl}[\mathrm{pH} 8.0], 2.5 \mathrm{mmol} / 1 \mathrm{CaCl}_{2}, 0.02 \%$ [wt/vol] $\mathrm{Na}_{3} \mathrm{~N}$ ) for $72 \mathrm{~h}$ at $37^{\circ} \mathrm{C}$. Lytic bands corresponding to the latent form of MMP2 (65 kDa) and MMP9 (92 kDa) were analysed as a total activity and visualised by staining with $0.5 \%$ (wt $/ \mathrm{vol}$ ) Coomassie Brilliant Blue solution (Sigma-Aldrich, Milan, Italy). Signal strengths were quantified using a densitometric program (NIH).

The MMP2 and MMP9 concentration in the surnatants was assessed by using commercially available immunoadsorbent assay kits (Amersham Pharmacia Biotech). All assays were run in duplicate, and levels were normalised by total protein content. The intra-assay coefficient of variation was between 5.5 and $7.0 \%$ for MMP2 and between 5.5 and $6.5 \%$ for MMP9.

\section{IL6 secretion}

IL6 release was measured by an enzyme-linked immunosorbent assay using a biotin-conjugated monoclonal antiIL6 antibody (Bioscience, San Diego, CA, USA). The assay sensitivity was less than $2 \mathrm{pg} / \mathrm{ml}$, and the inter-assay coefficient of variation was $5.2 \%$.

\section{Total RNA isolation and cDNA preparation}

Human fibroblast culture cells were collected at $-20^{\circ} \mathrm{C}$ in RNA Later. After removing RNA Later, total RNA was isolated using RNeasy Mini Kit (Qiagen, Hilden, Germany). RNA was quantified by measuring absorbance at 260 and $280 \mathrm{~nm}$. The integrity of the RNA was then checked by visual inspection of the two ribosomal RNAs, $18 \mathrm{~S}$ and $28 \mathrm{~S}$, on $1 \%$ agarose gel. Average yields of total RNA were $10 \pm 1 \mu \mathrm{g}$ per $8 \times 10^{5}$ cells. Isolated RNA was stored at $-80^{\circ} \mathrm{C}$ until quantification of the target mRNAs. For first-strand cDNA synthesis, $1 \mu \mathrm{g}$ total RNA was reverse-transcribed in a $20-\mu l$ volume using a cDNA synthesis kit (First strand cDNA Synthesis Kit for RT-PCR, AMV; Roche, Indianapolis, IN, USA) with random hexamers as primers, according to the manufacturer's instructions.

Quantification of TGFB1 and hypoxanthine-phosphoribosyltransferase gene expression

Relative quantification of the mRNAs was performed by real-time PCR using a Light-Cycler instrument (Roche Diagnostics, Mannheim, Germany). Gene-specific primers for the target gene $(T G F B 1)$ and reference gene hypoxanthine-phosphoribosyl-transferase (HPRT) were designed in our laboratory. Quantification of HPRT mRNA was used for sample normalisation. One microlitre of cDNA was brought to a final volume of $20 \mu \mathrm{l}$ in a glass capillary containing $1 \times$ LightCycler-FastStar DNA Master SYBR Green I mix (Roche Diagnostics), $4.5 \mathrm{mmol} / 1 \mathrm{MgCl}_{2}$, and $0.3 \mu \mathrm{mol} / 1$ of primers (Proligo, Paris, France) for $T G F B 1$ or $0.1 \mu \mathrm{mol} / 1$ for $H P R T$. Human TGFB1 primers were: sense: CTACTACGCCAAGGAGGTCAC, antisense: TTGCT GAGGTATCGCCAGGAA, product size 202 bp, gene bank accession number NM000660. Human HPRT primers were: sense: TGCTGACCTGCTGGATTACAT, antisense: TTGC GCACCTTGACCATCTTT, product size $249 \mathrm{bp}$, gene bank accession number M31642. PCR was performed with 10 min of initial denaturation and then 40 cycles of $10 \mathrm{~s}$ at $95^{\circ} \mathrm{C}$ (denaturation), $7 \mathrm{~s}$ at $58^{\circ} \mathrm{C}$ (annealing), and $13 \mathrm{~s}$ at $72^{\circ} \mathrm{C}$ (extension). The run was finished with one cycle at $40^{\circ} \mathrm{C}$ for $15 \mathrm{~s}$. Fluorescent data were acquired at the end of each extension phase. After amplification, a melting curve analysis from 65 and $95^{\circ} \mathrm{C}$ with heating rate of $0.1{ }^{\circ} \mathrm{C} / \mathrm{s}$ with a continuous fluorescence acquisition was done. A basal sample total RNA (untreated cells) was used to construct standard curves. In summary, after RNA reverse transcription, the cDNA was diluted into fourfold serial dilution (1:3 to $1: 81)$ and both genes (target and reference) were amplified. The standard curve was used to assess PCR efficiency. Standard curves were accepted only if the slope for each gene was around -3 with an $r$ value $>0.98$. Each cDNA was quantified in triplicate. For the relative quantification of samples, we used the software package Relative Quantification (Light Cycler, Roche, Milan, Italy). Results were expressed as the target : reference ratio of each sample, normalised by the target : reference ratio of the calibrator. The calibrator used for each PCR run was the sample with a dilution of $10^{-3}$ utilised in the standard curve. In the present data, the variation in measurements for the target gene in each sample ranged between 0 and $10 \%$.

Fibronectin determination

Fibronectin concentrations in supernatants were measured using a kit (QuantiMatrix human ELISA; Chemicon Intl, Temecula, CA, USA) according to the manufacturer's instructions. Data are expressed as $\mathrm{ng} \mathrm{ml}^{-1} 1.5 \times 10^{-5}$ cells.

\section{Statistical analysis}

Results are expressed as mean $\pm \mathrm{SD}$. Statistical comparisons between groups were performed by two-way ANOVA, with glucose concentration and Hcy dose as the factors; their interaction was also calculated. Post hoc 
Fig. 1 Effect of homocysteine on MMP2 and MMP9 protein production in human fibroblasts grown in the presence of 5.5 (Eu) and 22 (Hyper) mmol/l glucose concentrations. a Western blots representative of ten blots (two in each cell batch for each protein). $\mathbf{b}$, $\mathbf{c}$ Mean \pm SD of the densitometric analyses of all the experiments for MMP2 and MMP9 respectively. Data, in arbitrary units (AU), assuming $\beta$-actin expression equal to 100 $\mathrm{AU}$ in all experimental conditions. Light grey columns, unstimulated cells; dark grey columns, cells treated with $10 \mu \mathrm{mol} / 1$ homocysteine; black columns, cells treated with $100 \mu \mathrm{mol} / 1$ homocysteine

a

MMP2

$5.5 \mathrm{mmol} / \mathrm{l}$ glucose

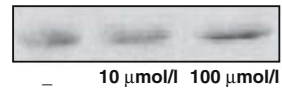

$22 \mathrm{mmol} / \mathrm{l}$ glucose
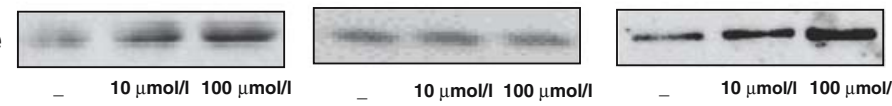

$10 \mu \mathrm{mol} / \mathrm{l} 100 \mu \mathrm{mol} /$

b

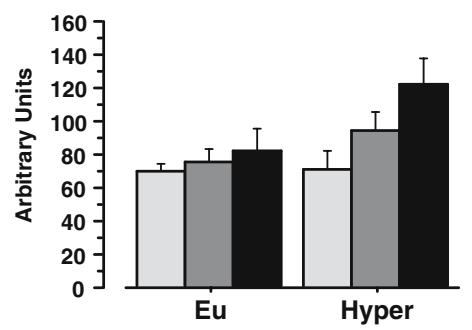

B-ACTIN
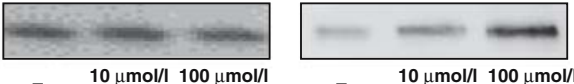

Hcy comparisons were carried out using the Bonferroni-Dunn test. Results were considered significant at $p<0.05$.

\section{Results}

As shown in Fig. 1, Hcy increased the production of MMP2 and MMP9 in a dose-dependent fashion ( $p<0.001$ for both) at $5.5 \mathrm{mmol} / \mathrm{l}$ and at $22 \mathrm{mmol} / 1$ glucose $(p<0.0001$ for both proteins), this effect being more pronounced $(p<0.0001$ and $p=0.018$ for the interaction terms, respectively for MMP2 and MMP9) in cells grown at high than in those grown at low glucose concentrations. Similarly, the production of
TIMP1, the physiological inhibitor of MMP2, was dosedependently suppressed by Hcy in both high and low glucose $(p<0.0001)$. TIMP1 production was higher $(p<0.0001)$ in fibroblasts cultured in high glucose without Hcy addition, and the inhibitory effect of Hcy was more pronounced than in low glucose $(p<0.0001)$ (Fig. 2).

In keeping with the Hcy-induced increase in production, the enzymatic activity of MMP2 and MMP9 was enhanced, with densitometric analysis of zymographic bands showing that both high glucose $(p<0.0001$ and $p=0.0007$, respectively) and Hcy ( $p<0.0001$ for both proteins) independently increased activity. As was the case for expression levels, high glucose amplified the effect of Hcy $(p<0.01$ and
Fig. 2 Effect of homocysteine on TIMP1 protein production in human fibroblasts grown in the presence of $5.5(\mathrm{Eu})$ and 22 (Hyper) mmol/1 glucose concentrations. a Western blot representative of ten blots (two in each cell batch). b Mean \pm SD of the densitometric analysis of the ten experiments for TIMP1. Data, in arbitrary units (AU), assuming $\beta$-actin expression equal to $100 \mathrm{AU}$ in all experimental conditions. Light grey columns, unstimulated cells; dark grey columns, cells treated with $10 \mu \mathrm{mol} / 1$ homocysteine; black columns, cells treated with $100 \mu \mathrm{mol} / 1$ homocysteine $\mathbf{a}$
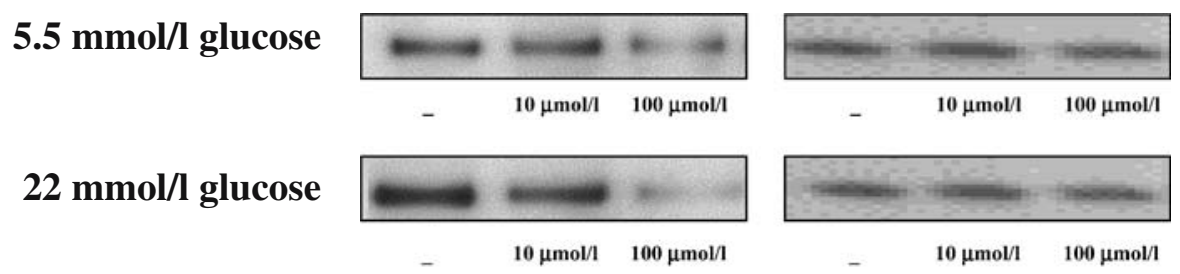

Hcy

b

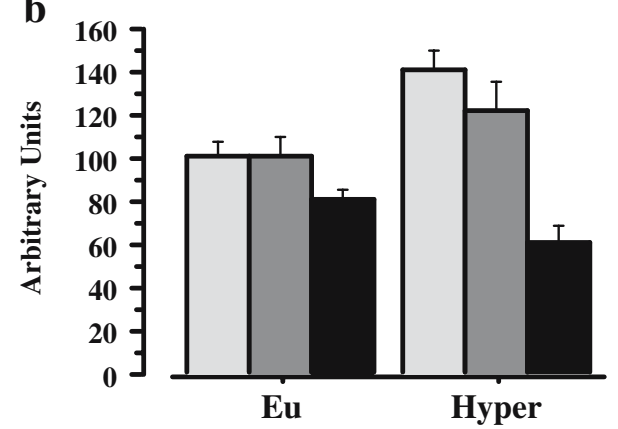


Fig. 3 Effect of homocysteine on MMP2 and MMP9 activity in human fibroblasts grown in the presence of $5.5(\mathrm{Eu})$ and 22 (Hyper) $\mathrm{mmol} / \mathrm{l}$ glucose concentrations. a Gelatin zymograms representative of ten (two in each cell batch for each protein). $\mathbf{b}, \mathbf{c}$ Mean $\pm \mathrm{SD}$ of the densitometric analyses of all experiments for MMP2 and MMP9, respectively. Data are expressed as \% above basal activity. Grey columns, cells treated with $10 \mu \mathrm{mol} / 1$ homocysteine; black columns, cells treated with $100 \mu \mathrm{mol} / 1$ homocysteine a

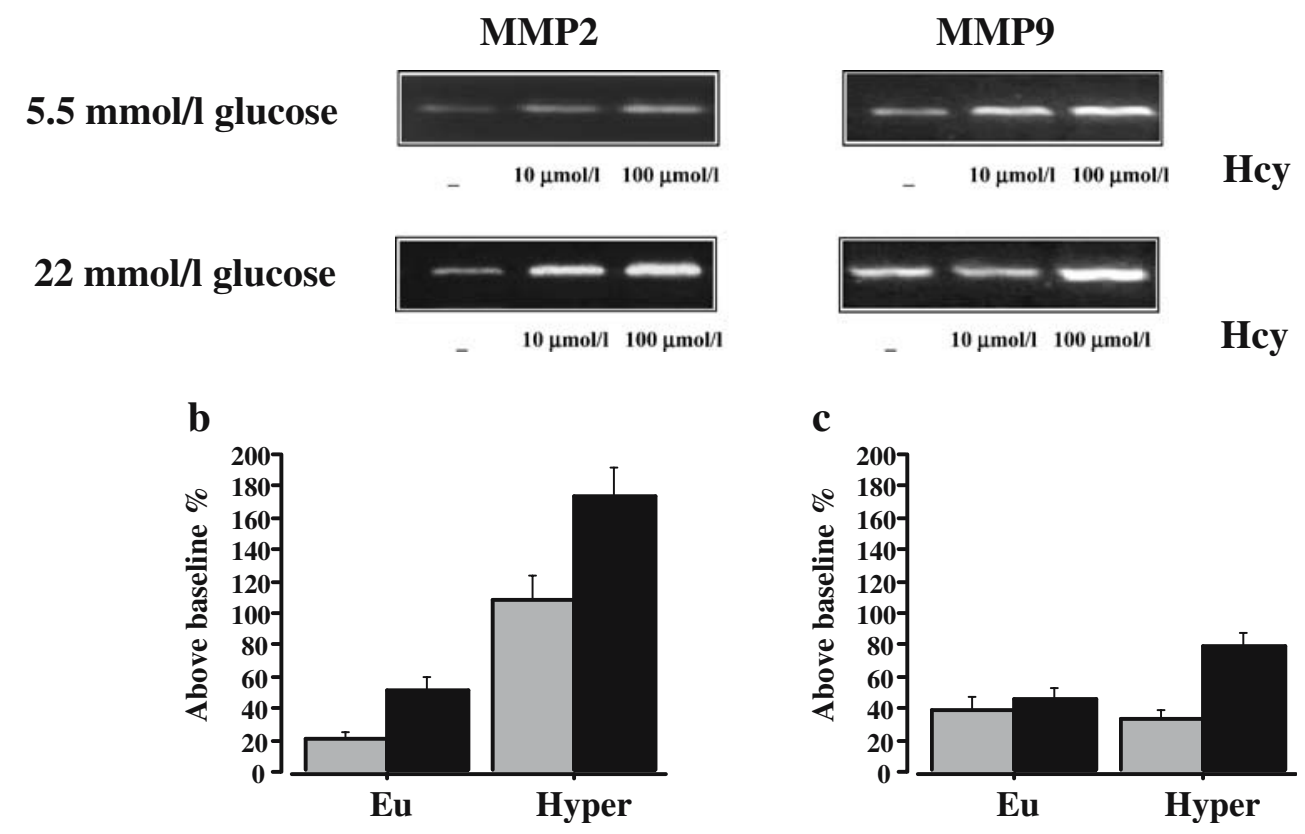

$p<0.0001$ respectively for MMP2 and MMP9). The effects on enzymatic activity were more pronounced for MMP2 than MMP9 (Fig. 3).

IL6 release was markedly more stimulated in cells grown at $22 \mathrm{mmol} / \mathrm{l}$ than in those grown at $5.5 \mathrm{mmol} / \mathrm{l}$ glucose $(p<0.0001)$ (Fig. 4). Hcy dose-dependently increased $(p<0.0001)$ IL6 release to similar degrees at high and low glucose concentrations $(p=0.36)$, with the two Hcy doses producing an equivalent effect ( $p=0.33$ by the BonferroniDunn test). Pre-incubation with the NF-KB inhibitor NAC abolished Hcy-induced stimulation at both glucose levels $(p<0.002$ vs the value with $100 \mu \mathrm{mol} / 1 \mathrm{Hcy}$ at low glucose, and $p<0.0001$ vs the value with $100 \mu \mathrm{mol} / 1 \mathrm{Hcy}$ at high glucose, Bonferroni-Dunn). Similar results were obtained by $1 \mathrm{mmol} / \mathrm{l}$ EGTA (data not shown); indeed, calphostin C, a powerful inhibitor of both NF- $\mathrm{BB}$ activation and protein kinase $\mathrm{C}$ (PKC), reduced IL6 release from cells grown at

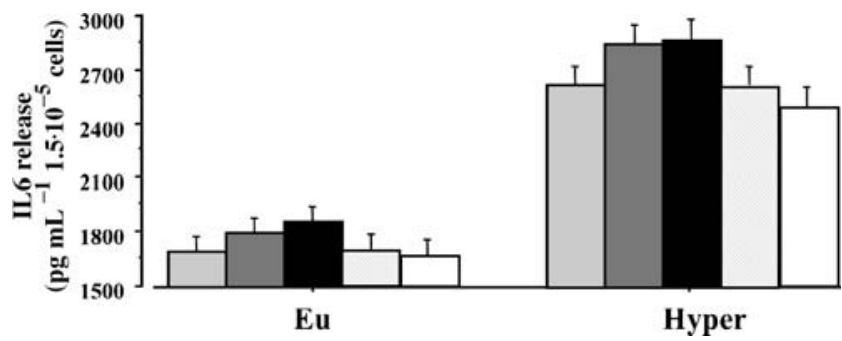

Fig. 4 Effect of homocysteine on IL6 release from human fibroblasts grown in the presence of $5.5(\mathrm{Eu})$ and 22 (Hyper) mmol/l glucose concentrations. Light grey columns, unstimulated cells; dark grey columns, cells treated with $10 \mu \mathrm{mol} / 1$ homocysteine; black columns, cells treated with $100 \mu \mathrm{mol} / 1$ homocysteine; hatched columns, cells treated with $10 \mathrm{mmol} / \mathrm{l} N$-acetyl-L-cysteine plus $100 \mu \mathrm{mol} / 1$ homocysteine; white columns, cells treated with $10 \mathrm{nmol} / 1$ calphostin $\mathrm{C}$ plus $100 \mu \mathrm{mol} / 1$ homocysteine high glucose to a lower level than in the unstimulated state $(p<0.05)$.

To test whether the NF-KB inhibitors could also influence the MMP-TIMP pathway, we measured MMP2 and MMP9 release in the culture medium of cells treated with $100 \mu \mathrm{mol} / 1 \mathrm{Hcy}$ and NAC or calphostin C. Data are reported in Table 1. Similarly to IL6, Hcy-induced release of both MMP2 and -9 was significantly reduced when cells were pretreated with NF-KB inhibitors.

Neither TGFB1 expression nor release (Table 2) differed significantly between cells grown in high or low glucose, with or without Hcy. On the other hand, fibronectin concentrations in the supernatants of the same cell batches were higher $(p<0.0001)$ with high than low glucose, whereas Hcy had no influence under either condition (Fig. 5).

\section{Discussion}

The main result of this study was that, in primary human fibroblasts, high glucose and homocysteine synergistically modulate MMP-TIMP pathways; this joint effect was not, however, exerted on the signalling pathway involving TGFB1 expression or production of cell matrix components.

MMPs are regulated by a variety of inflammatory cytokines, hormones and growth factors, as well as by shear and oxidative stress, all of which are known to be operative within the vessel wall. Vulnerable regions of human atherosclerotic plaques display increased expression and activity of MMP1, -3 and -9 , which promote matrix degradation with subsequent plaque destabilisation and 
Table 1 MMP2 and MMP9 release from human fibroblasts in the unstimulated condition and after $6 \mathrm{~h}$ of stimulation with Hcy $100 \mu \mathrm{mol} / \mathrm{l}$, with and without NF- $\mathrm{KB}$ inhibitors

\begin{tabular}{|c|c|c|c|c|}
\hline & \multicolumn{2}{|l|}{ MMP2 } & \multicolumn{2}{|l|}{ MMP9 } \\
\hline & $5.5 \mathrm{mmol} / \mathrm{l}$ & $22 \mathrm{mmol} / \mathrm{l}$ & $5.5 \mathrm{mmol} / \mathrm{l}$ & $22 \mathrm{mmol} / \mathrm{l}$ \\
\hline Unstimulated cells & $6.50 \pm 2.12$ & $11.75 \pm 1.26$ & $0.25 \pm 0.07$ & $0.62 \pm 0.05$ \\
\hline Hcy $100 \mu \mathrm{mol} / \mathrm{l}$ & $16.20 \pm 1.41$ & $35.31 \pm 4.24$ & $0.95 \pm 0.21$ & $1.23 \pm 0.08$ \\
\hline Hcy + NAC & $7.23 \pm 1.30^{*}$ & $12.50 \pm 0.71 *$ & $0.31 \pm 0.10 *$ & $0.54 \pm 0.14 *$ \\
\hline $\mathrm{Hcy}+$ calphostin $\mathrm{C}$ & $6.86 \pm 1.74 *$ & $12.92 \pm 0.96^{*}$ & $0.30 \pm 0.06^{*}$ & $0.57 \pm 0.09 *$ \\
\hline
\end{tabular}

Data, expressed as ng/mg protein, are mean $\pm \mathrm{SD}$

$N A C N$-acetyl-L-cysteine

$* p<0.005$ vs Hcy $100 \mu \mathrm{mol} / 1$

rupture in these areas. As already described in other cell types [31], we observed enhanced MMP production in cells grown in the presence of high glucose. This effect was not due to increased osmolality, because no change in MMP2 or MMP9 were observed with equimolar concentrations of mannose (data not shown). High glucose may increase MMP production and activity either directly or indirectly (e.g. via oxidative stress or advanced glycation products).

Similarly to high glucose, homocysteine enhances MMP2 and -9 production and activity in human fibroblasts. This effect, already documented in endothelial cells [21], could be part of the atherogenic effect of homocysteine, potentially leading to degradation of ECM within the atherosclerotic lesion. Additionally, the increased MMP production could enhance another key early event in atherogenesis, namely monocyte migration into the subintima. The mechanism for the association between MMP and Hcy is not fully understood. Studies suggest that Hcy might stimulate MMP9 expression via an NF- $\mathrm{kB}$-activating mechanism, resulting in enhanced cytokine production [32] (NF- $\mathrm{KB}$ plays an essential role in the transcriptional activation of IL6 induced by various stimuli). Our finding that three different inhibitors of NF- $\mathrm{KB}$ activation reversed the Hcy-induced IL6 release in cells grown in low as well as high glucose is in keeping with this view, and the observation of a parallel inhibitory effect of both NAC and calphostin C on MMP release confirms a link between MMP and cytokine production [33].

Beside its effect on NF-kB, calphostin $\mathrm{C}$ is a powerful and specific PKC inhibitor. Thus, its ability to reverse Hcy effects confirms the already described ability of homocysteine to activate PKC [34] and is in agreement with recent observations in endothelial cells, where both staurosporine (a PKC inhibitor) and NAC reduced homocysteine-induced MMP9 activation [35].

In endothelial cells, Hcy was also able to increase TIMP1 activity, probably via $\mathrm{O}_{2}$ production [21]; similarly, in rat mesangial cells Hcy enhanced TIMP1 production, thereby promoting mesangial expansion, ECM accumulation, and eventually kidney fibrosis [20]. In our experimental model, TIMP1 expression was dose-dependently reduced by Hcy. Thus, fibroblasts may be involved not just in the accumulation of ECM, but also in matrix degradation, hence promoting plaque instability.

The direct effect of Hcy on TGFB1 expression and on matrix deposition, a process typically mediated by this growth factor, was examined. In our experimental model, Hcy did not appreciably influence either TGFB1 expression or fibronectin release, nor did it synergise the effect of high glucose on fibronectin release. These findings suggest that Hcy might exert its detrimental effect on the vasculature by mechanisms independent of the paracrine-autocrine activity of TGFB.

Table 2 TGFB1 expression and release in human fibroblasts in the unstimulated condition and after $6 \mathrm{~h}$ of stimulation with different concentrations of Hcy

\begin{tabular}{|c|c|c|c|c|}
\hline & \multicolumn{2}{|c|}{$5.5 \mathrm{mmol} / 1$ glucose } & \multicolumn{2}{|c|}{$22 \mathrm{mmol} / 1$ glucose } \\
\hline & Expression $^{\mathrm{a}}$ & Release $^{\mathrm{b}}$ & Expression $^{\mathrm{a}}$ & Release $^{\mathrm{b}}$ \\
\hline Unstimulated cells & $0.97 \pm 0.36$ & $5.63 \pm 1.05$ & $1.35 \pm 0.70$ & $5.13 \pm 0.84$ \\
\hline Hcy $10 \mu \mathrm{mol} / 1$ & $1.28 \pm 0.51$ & $5.34 \pm 0.86$ & $1.11 \pm 0.40$ & $4.84 \pm 1.13$ \\
\hline Hcy $100 \mu \mathrm{mol} / 1$ & $1.18 \pm 0.46$ & $5.71 \pm 1.31$ & $1.31 \pm 0.62$ & $4.96 \pm 0.94$ \\
\hline
\end{tabular}

Data are $\operatorname{mean} \pm \mathrm{SD}$

${ }^{\text {a }}$ Expressed in arbitrary units as ratio between TGFB1 and HPRT

${ }^{\mathrm{b}}$ Expressed as $\mathrm{ng} \mathrm{m}^{-1} 1.5 \times 10^{-5}$ cells 


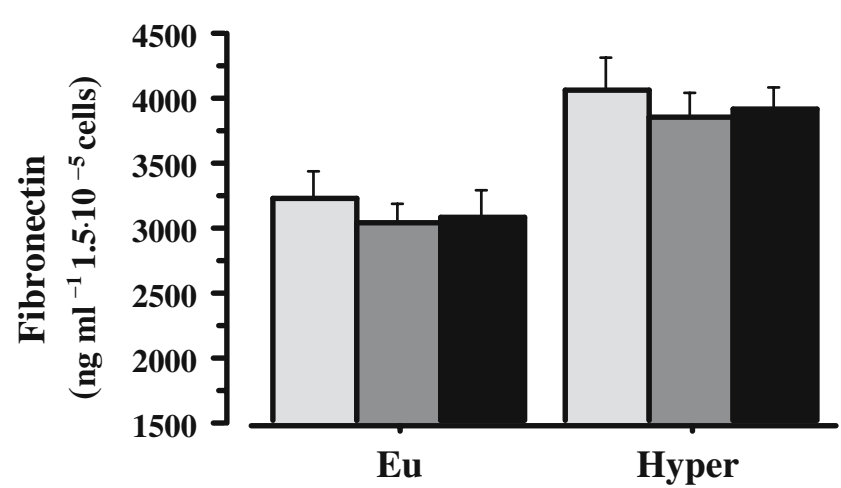

Fig. 5 Effect of homocysteine on fibronectin release from human fibroblasts grown in the presence of $5.5(\mathrm{Eu})$ and 22 (Hyper) mmol/1 glucose concentrations. Light grey columns, unstimulated cells; dark grey columns, cells treated with $10 \mu \mathrm{mol} / 1$ homocysteine; black columns, cells treated with $100 \mu \mathrm{mol} / 1$ homocysteine

In conclusion, in human skin fibroblasts, homocysteine upregulates the MMP-TIMP pathway and IL6 release, effects that are amplified in the presence of high glucose concentrations. As the proliferative pathway TGFB-fibronectin is not influenced by co-incubation with homocysteine and high glucose whereas IL6 is affected, Hcy would seem to act more like an inflammatory than a proliferative stimulus. Through these actions, homocysteine might contribute to the increased plaque instability in diabetic patients with poor metabolic control.

\section{References}

1. Libby P (2003) Vascular biology of atherosclerosis: overview and state of the art. Am J Cardiol 91:3A-6A

2. Ikeda U, Shimada K (2003) Matrix metalloproteinases and coronary artery diseases. Clin Cardiol 26:55-59

3. Li Z, Li L, Zielke HR et al (1996) Increased expression of 72-kd type IV collagenase (MMP-2) in human aortic atherosclerotic lesions. Am J Pathol 148:121-128

4. Knox JB, Sukhova GK, Whittemore AD, Libby P (1997) Evidence for altered balance between matrix metalloproteinases and their inhibitors in human aortic diseases. Circulation 95:205-212

5. Brew K, Dinakarpandian D, Nagase H (2000) Tissue inhibitors of metalloproteinases: evolution, structure and function. Biochim Biophys Acta 1477:267-283

6. Fielitz J, Leuschner M, Zurbrugg HR et al (2004) Regulation of matrix metalloproteinases and their inhibitors in the left ventricular myocardium of patients with aortic stenosis. J Mol Med 82:809-820

7. Hemmerlein B, Johanns U, Halbfass J et al (2004) The balance between MMP-2/-9 and TIMP-1/-2 is shifted towards MMP in renal cell carcinomas and can be further disturbed by hydrogen peroxide. Int J Oncol 24:1069-1076

8. Bennermo M, Held C, Green F et al (2004) Prognostic value of plasma interleukin- 6 concentrations and the $-174 \mathrm{G}>\mathrm{C}$ and -572 $\mathrm{G}>\mathrm{C}$ promoter polymorphisms of the interleukin- 6 gene in patients with acute myocardial infarction treated with thrombolysis. Atherosclerosis 174:157-163

9. Cai WJ, Koltai S, Kocsis E et al (2003) Remodeling of the adventitia during coronary arteriogenesis. Am J Physiol Heart Circ Physiol 284:H31-H40
10. Solini A, Chiozzi P, Falzoni S, Morelli A, Fellin R, Di Virgilio F (2000) High glucose modulates P2X7 receptor-mediated function in human primary fibroblasts. Diabetologia 43:1248-1256

11. Solini A, Chiozzi P, Morelli A et al (2004) Enhanced P2X7 activity in human fibroblasts from diabetic patients: a possible pathogenetic mechanism for vascular damage in diabetes. Arterioscler Thromb Vasc Biol 24:1240-1245

12. Villacorta L, Graca-Souza AV, Ricciarelli R, Zingg JM, Azzi A (2003) Alpha-tocopherol induces expression of connective tissue growth factor and antagonizes tumor necrosis factor-alphamediated downregulation in human smooth muscle cells. Circ Res 92:104-110

13. Vrancken Peeters MP, Gittemberger-de Groot AC, Mentink MM, Poelmann RE (1999) Smooth muscle cells and fibroblasts of the coronary arteries derive from epithelial-mesenchymal transformation of the epicardium. Anat Embryol 199:367-378

14. Fruchart JC, Nierman MC, Stroes ES, Kastelein JJ, Duriez P (2004) New risk factors for atherosclerosis and patient risk assessment. Circulation 109 (Suppl 1):III15-III19

15. Taylor LM Jr (2003) Elevated plasma homocysteine as risk factor for peripheral arterial disease-what is the evidence? Semin Vasc Surg 16:215-222

16. Spencer CG, Martin SC, Felmeden DC, Blann AD, Beevers GD, Lip GY (2004) Relationship of homocysteine to markers of platelet and endothelial activation in "high risk" hypertensives: a substudy of the Anglo-Scandinavian Cardiac Outcomes Trial. Int J Cardiol 94:293-300

17. Romerio SC, Linder L, Nyfeler J et al (2004) Acute hyperhomocysteinemia decreases NO bioavailability in healthy adults. Atherosclerosis 176:337-344

18. Mahfouz MM, Kummerow FA (2004) Vitamin C or Vitamin B6 supplementation prevent the oxidative stress and decrease of prostacyclin generation in homocysteinemic rats. Int $\mathrm{J}$ Biochem Cell Biol 36:1919-1932

19. Zeng X, Dai J, Remick DG, Wang X (2003) Homocysteinemediated expression and secretion of monocyte chemoattractant protein-1 and interleukin- 8 in human monocytes. Circ Res 93:311-320

20. Yang ZZ, Zou AP (2003) Homocysteine enhances TIMP-1 expression and cell proliferation associated with NADH oxidase in rat mesangial cells. Kidney Int 63:1012-1020

21. Shastry S, Tyagi SC (2004) Homocysteine induces metalloproteinase and shedding of beta-1 integrin in microvessel endothelial cells. J Cell Biochem 93:207-213

22. Holven KB, Halvorsen B, Schulz H, Aukrust P, Ose L, Nenseter MS (2003) Expression of matrix metalloproteinase-9 in mononuclear cells of hyperhomocysteinaemic subjects. Eur J Clin Invest 33:555-560

23. van Aken BE, Jansen J, van Deventer SJ, Reitsma PH (2000) Elevated levels of homocysteine increase IL-6 production in monocytic Mono Mac 6 cells. Blood Coagul Fibrinolysis 11: $159-164$

24. Dalal S, Parkin SM, Homer-Vanniasinkam S, Nicolaou A (2003) Effect of homocysteine on cytokine production by human endothelial cells and monocytes. Ann Clin Biochem 40:534-541

25. Meigs JB, Jacques PF, Selhub J et al (2001) Fasting plasma homocysteine levels in the insulin resistance syndrome: the Framingham Offspring Study. Diabetes Care 24:1403-1410

26. Hoogeveen EK, Kostense PJ, Beks PJ et al (1998) Hyperhomocysteinemia is associated with an increased risk of cardiovascular disease, especially in non-insulin-dependent diabetes mellitus: a population-based study. Arterioscler Thromb Vasc Biol 18:133-138

27. Diakoumopoulou E, Tentolouris N, Kirlaki E et al (2005) Plasma homocysteine levels in patients with type 2 diabetes in a 
Mediterranean population: relation with nutritional and other factors. Nutr Metab Cardiovasc Dis 15:109-117

28. Mazza A, Bozzone E, Mazza F, Distante A (2005) Reduced serum homocysteine levels in type 2 diabetes. Nutr Metab Cardiovasc Dis 15:118-124

29. Rudy A, Kowalska I, Straczkowski M, Kinalska I (2005) Homocysteine concentrations and vascular complications in patients with type 2 diabetes. Diabetes Metab 31:112-117

30. Emoto M, Kanda H, Shoji $T$ et al (2001) Impact of insulin resistance and nephropathy on homocysteine in type 2 diabetes. Diabetes Care 24:533-538

31. Death AK, Fisher EJ, McGrath KC, Yue DK (2003) High glucose alters matrix metalloproteinase expression in two key vascular cells: potential impact on atherosclerosis in diabetes. Atherosclerosis 168:263-269
32. Wang G, Siow YL, OK (2001) Homocysteine induces monocyte chemoattractant protein-1 expression by activating NF-kappaB in THP-1 macrophages. Am J Physiol Heart Circ Physiol 280: $\mathrm{H} 2840-\mathrm{H} 2847$

33. Distler JH, Jungel A, Huber LC et al (2005) The induction of matrix metalloproteinase and cytokine expression in synovial fibroblasts stimulated with immune cell microparticles. Proc Natl Acad Sci USA 102:2892-2897

34. Jiang X, Yang F, Tan H et al (2005) Hyperhomocystinemia impairs endothelial function and eNOS activity via PKC activation. Arterioscler Thromb Vasc Biol 25:2515-2521

35. Moshal KS, Sen U, Tyagi N et al (2006) Regulation of homocysteine-induced MMP-9 by extracellular regulated protein kinase-1/2 (ERK-1/2) pathway. Am J Physiol Cell Physiol $290: 883-891$ 